EDITORIAL

\title{
MOVING TOWARDS THE NEXT LEVEL...
}

\author{
Chris O'Connor MSc EdD ${ }^{1^{*}}$ \\ 1 Clinical Education Consultant, Emergency Medical Training, Ireland.
}

*chris.oconnor.ie@gmail.com

\section{Introduction}

Since the turn of the century, significant progressive changes have taken place in the provision of prehospital emergency care in Ireland. Few would have dared to imagine the scale of advancement both in terms of education and scope of practice that has taken place since the bells tolled to herald the arrival of the new millennium. Academically, paramedics in Ireland who for over 20 years have been qualified at diploma level now have the opportunity to qualify with an honours bachelor of science degree, and the possibility of progression to masters and doctoral degrees should they feel so inclined. From a clinical perspective, the Advanced Life Support service that is available nationwide today has evolved from an emergency service provided by EMTs just a few short years ago.

In order to make the step up to the next level in our development as a bona fide recognised profession, it is essential that we embark on the journey of the development of our own body of knowledge in relation to our education, our practice and our profession as a whole. The development of research capacity within the paramedic profession is a subject which will be addressed by Alan Batt, Vice-President of the Irish College of Paramedics (ICoP), at the upcoming ICoP Scientific Symposium. There is little doubt that the development of a substantial cohort of doctoral level researchers within our profession will certainly take time, not to mention a significant change in organisational culture, and practitioners on the ground may legitimately ask, 'what can I do about it?', or 'what has this got to do with me?'. I propose that a very good place for practitioners with an interest in developing research skills to start is to become researchers in their own practice by becoming reflective practitioners. I realise that until relatively recently very few pre-hospital practitioners in Ireland would have considered themselves in the role of 'the researcher', traditionally it simply has not been part of our culture. However, with a little guidance and by using a structured reflective model such as Gibbs Reflective Cycle (1) getting started as a reflective practitioner is not as daunting as it first appears, and now more than ever there are an increasing number of opportunities to share the fruits of your research at events such as the ICoP Scientific Symposium and CPC Study Days or at the EMS Gathering, or by publication in a journal such as this.

The term 'reflective practice' is one of those concepts that appears to have been around forever. However, it has only been as recently as the mid 1980's that reflective practice has been formally acknowledged and adopted, particularly in nursing education, as a key strategy for learning. Influenced by the work of Schön, who identified reflective practice as one of the main ways in which professionals learn, it has become one of the cornerstones of medical education for nurses, doctors, and many of the other allied healthcare professions. Schön (2, p. 49-50) describes how the everyday life of the professional practitioner is dependent upon tacit knowledge which may be described as 'expertise, know-how, and information that employees have developed through experience' (3). This tacit knowledge, which has been accumulated through experience and reflection-on-action, enables the practitioner to think about their actions and if necessary adjust their performance, often while they are in the middle of performing complex tasks. Schön describes this ability as reflection-in-action, and goes on to defend the legitimacy and the value of the knowledge generated by reflective practitioners:

When someone reflects-in-action, he becomes a researcher in the practice context. He is not dependent on the categories of established theory and technique, but constructs a new theory of the unique case. (2, p. 68). 
Garavan et al. (3) further emphasise the value of tacit knowledge in an organisational context when they argue that for an organisation to maintain a competitive edge it must fully utilise the tacit knowledge possessed by its employees. They suggest that this may be best achieved in a supportive working environment with a high level of organisational trust, good working relationships, and a good learning environment.

In the area of pre-hospital emergency care in Ireland, it is only in the last decade that the notion of reflective practice has been tentatively approached. Indeed, until recently it has largely been ignored as practitioners and educators alike have been slow to engage with this new strategy for learning. Now however, regulatory bodies such as the Pre-Hospital Emergency Care Council (PHECC) in Ireland (4, 5), and the Health \& Care Professions Council (HCPC) in the UK (6), have begun to offer Continuous Professional Competency (CPC) education points for case studies, reflections and reflective journals and consequently this validation by the main statutory regulators has ignited interest and curiosity around the process of learning through reflective practice.

A key element of the reflective practice concept is that of reflective learning. Bulman (7, p. 4) emphasises that learning is the central purpose of reflection and reflective practice. He describes it as 'the exploration of experience, the analysis of feelings as well as oneself to inform learning'.

While there is no doubting the popularity of reflective practice among students, practitioners and educators alike it is not without its detractors. While many are convinced of its value, 'others see it as self-indulgent naval gazing' (8, p. 2). Sceptics, mainly from an empirical epistemological perspective, include Clinton (9) who seriously questions the value of reflective practice as a learning method and Newell (10) who argues that reflection may be fundamentally flawed due to issues surrounding the accuracy of the reflection and the bias of the practitioner. Newell (11) also laments that the lack of clarity of the process of assessment and evaluation of reflection may be viewed as an obstacle to its promotion. However, Jasper points to the value of the new knowledge generated when put into practice, she writes:

'Reflective practice builds on the notions of reflection and reflective learning by adding some sort of action into the equation, thus: Experience + reflection + learning $\rightarrow$ change in behaviour or action' $(12, \mathrm{p} .43)$.

From my own engagement with practitioners and educators over the course of a recent research project there is little doubt that the idea of being a reflective practitioner is seen as desirable. However, it is also clear that quite a lot of confusion exists among practitioners and educators about what it actually means to be a reflective practitioner. In an online questionnaire survey of practitioners representing the full spectrum of Irish EMS contexts and all three clinical levels of practitioner, $65.6 \%$ of respondents indicated that they considered themselves to be reflective practitioners, while $7 \%$ said that they did not. The remaining $27.4 \%$ indicating that they were unsure. Of the $65.6 \%(122$ practitioners) who indicated that they considered themselves to be reflective practitioners, only 13 indicated that when reflecting on their practice they used a structured model of reflection.

Many practitioners described various informal strategies for reflection either collaboratively or alone, citing methodologies such as case debriefing, conversations and discussions with colleagues 'over a cup of tea', reading journals, research, attend clinical audit meetings, online education programmes, and general personal reflections. While all of these strategies are helpful and beneficial, and I would not question the sincerity or the motivation of the respondents, educators who participated in the process were unanimous in their preference for the use of a structured model of reflection as they felt it added rigour and credibility to the process.

Interestingly, in the organisational context, there appears to be a clear distinction between voluntary organisations and state-funded ambulance services in terms of their encouragement of reflective practice among their practitioners. $70 \%$ of practitioners from the voluntary organisations felt that reflective practice was encouraged by their respective organisations, compared with only $42 \%$ of practitioners who identified themselves as being employed in a state-funded ambulance service. It is difficult to explain why there should be such a difference, however one possible explanation is the fact that the statutory ambulance services have evolved from a relatively small 
population where there hasn't been a tradition, or a culture of reflection. By way of contrast the voluntary organisations are typically made up of people from a more diverse population, and a wide variety of professional backgrounds. It is possible that the volunteers have been engaged with reflection in their full-time careers and are more comfortable with both the concept and the process. Whatever the reason may be, I feel that this is a significant issue that requires further exploration.

In order to begin the process of growing the next generation of reflective practitioners and prehospital emergency care researchers, I believe it is critical that these essential skills relating to research methods and reflective practice be prominently emphasised in the education and training standards for practitioners at all levels (13), as it appears that their absence has resulted in their importance being omitted from most accredited EMS education programmes in Ireland, or at best been seen as an 'optional extra'. Education will also be required for existing practitioners and educators alike who, with their collective experience and wisdom, have much to offer in terms of the development of our profession.

As I mentioned at the outset, the development of our own body of knowledge in relation to our education, our practice and our profession as a whole represents the next challenge in the evolution of our profession. The question is: are we ready?

\section{References}

1. Gibbs, G. Learning by Doing: A Guide to Teaching and Learning Methods. Oxford: Oxford Further Education Unit. 1988.

2. Schön, D. A. The Reflective Practitioner. How Professionals Think in Action. New York: Basic Books. 1983.

3. Garavan, T., O'Brien, F., and Kiernan, V. Sharing knowledge is the key to a competitive edge. Learning and Development. Issue 21. p. 15-18. 2017.

4. PHECC. Clinical Professional Competence. [Online] Available from: https:// issuu.com/636764/docs/emt_professional_competence_booklet. 2013. [Accessed 8 May 2018].

5. Knox, S., Cullen, W., and Dunne, C. Continuous Professional Competence (CPC) for Irish paramedics and advanced paramedics: a national study. https:// bmcmededuc.biomedcentral.com/articles/10.1186/1472-6920-14-41. 2014. [Accessed 8 May 2018].

6. HCPC. Continuing Professional Development and Your Registration. http://www.hcpc -uk.org/assets/documents/10001314CPD_and_your_registration.pdf. 2017. [Accessed 8 May 2018].

7. Bulman, C. An introduction to reflection. IN: Bulman, C and Schutz, S. (eds.), Reflective Practice in Nursing. 5th ed. [Online] 2013. [Accessed 11 May 2017].

8. Finlay, L. Reflecting on 'Reflective Practice'. [Online] Available from: https:// pdfs.semanticscholar.org/c128/691f2615de873dfe544fcb5dc902fe812675.pdf. 2008. [Accessed 13 May 2017].

9. Clinton. M. On reflection in action: unaddressed issues in refocussing the debate on reflective practice. International Journal of Nursing Studies. Vol. 4. p. 197-203. 1998.

10. Newell. R. Anxiety, accuracy and reflection: the limits of professional development. Journal of Advanced Nursing. 17. p. 1326-1333.1992.

11. Newell. R. Reflection: art, science or pseudo-science? Nurse Education Today. Vol.14. p. 79-81. 1994.

12. Jasper, M. Vital Notes for Nurses. Professional Development, Reflection and Decision Making. Oxford: Blackwell. 2006.

13. PHECC. Education and Training Standards. [Online] Available from: http:// www.phecit.ie/PHECC/Education_and_careers/Education_and_training_standards/ PHECC/Education_and_careers/Education_and_Training_Standards/

Education_and_Training_Standards.aspx?Hkey=1733bd9d-1ea7-41e7-af20-

8ab0f40ab846. 2014. [Accessed 8 May 2018]. 